EJR 00041

\title{
Computed tomography of the human developing anterior skull base
}

\author{
J. Van Loosen ${ }^{1}$, A.I.J. Klooswijk ${ }^{2}$, D. van Velzen ${ }^{3}$ and C.D.A. Verwoerd ${ }^{1}$ \\ Departments of ${ }^{1}$ Otorhinolaryngology and ${ }^{2}$ Radiology, Dijkzigt Academic Hospital, University of Rotterdam, The Netherlands, and ${ }^{3}$ Department of \\ Fetal and Infant Pathology, RLCH Alder Hey, University of Liverpool, Liverpool, U.K.
}

(Received 20 November 1989; revised version received 20 December 1989; accepted 3 January 1990)

Key words: Computed tomography, skull base; Computed tomography, lamina cribrosa; Skull base, CT; Lamina cribrosa, ossification

\begin{abstract}
The ossification of the anterior skull base, especially the lamina cribrosa, has been studied by computed tomography and histopathology. Sixteen human fetuses, (referred to our laboratory for pathological examination after spontaneous abortion between 18 and 32 weeks of gestation) and three infants, (1, 2 and 6 years of age, respectively) were examined. The cartilaginous preformation of the anterior skull base creates a 'pseudo-defect' on CT in the coronal plane, even with ultra thin sections and high resolution CT. By the age of 6 years of life this 'artefact' is no longer, as the present ossification of the lamina cribrosa is, by that time, complete.
\end{abstract}

\section{Introduction}

Computed tomography (CT) is now widely used to investigate the abnormalities of the anterior skull base. However, little attention has been paid to the different manifestations of the developing and ossifying anterior skull base and to problems in the interpretation of CT in the first years of life.

Parts of the anterior skull base are formed by membranous ossification of fibrous tissue, whereas the anlage of other medial parts is cartilaginous [1-3] including the nasal septum and crista Galli [4]. The replacement of this cartilage by bone is not complete at birth and continues during childhood. The whole of the complex, consisting of the nasal septum, crista Galli, (cribriform plate) lamina cribrosa and lateral ethmoids initially develops as a cartilaginous structure [5-7]. In the neonate the nasal septum is still cartilaginous [8] and the upper lateral cartilages extend into the anterior base of the skull [9]. During further development of the infant, between the first and sixth year of life, ossification of the lamina cribrosa begins by fusion of the

Address for reprints: J. van Loosen, ENT Department, University Hospital Dijkzigt, Dr. Molewaterplein 40, 3015 GD Rotterdam, The Netherlands. ossifying nasal septum and the lateral ethmoid [7,10-12].

This study was carried out to evaluate the CT pattern of ossifying structures in humans.

\section{Materials and Methods}

\section{Fetal material}

Sixteen human fetuses, referred to our laboratory for pathological examination after spontaneous abortion evenly distributed between 18 and 32 weeks gestational age, were studied after routine fixation in $0.1 \mathrm{M}$ phosphate-buffered formaldehyde $4 \%(\mathrm{pH} 7.4)$.

\section{Infant material}

Mid-facial CT images were available in three children, (1,2 and 6 years of age, respectively), who had been assessed for neurological symptoms. The midfacial block specimen from the youngest child was also available for histology.

\section{Computed tomography}

CT of all fetal skulls was performed in coronal sections using a Philips Tomoscan 350 with contiguous $1.5 \mathrm{~mm}$ slices. In the children only those CT scans were used which were primarily acquired in a coronal plane 
with identical slice thickness and spacing, to avoid differences in resolution due to the method of data acquisition.

\section{Magnetic Resonance Imaging (MRI)}

For the documentation of the non-osseous cartilaginous structures, six representative fetal skulls were available. They were analysed in a previous collaborative study using MRI (Dyna scan, 4.2 tesla MRI Zentralforschungs Institut, Ciba-Geigy Basel) in the same plane $[4,13]$.

\section{Tissue processing and histology}

All mid-facial blocks were decalcified and embedded in paraffin. $5 \mu$ semiserial sections were cul in a frontal plane and stained with combined Alcian Blue/PAS stain.

\section{Results}

\section{Fetal age group}

In all stages histological analysis demonstrated that the medial anterior base of the skull was fully carti-

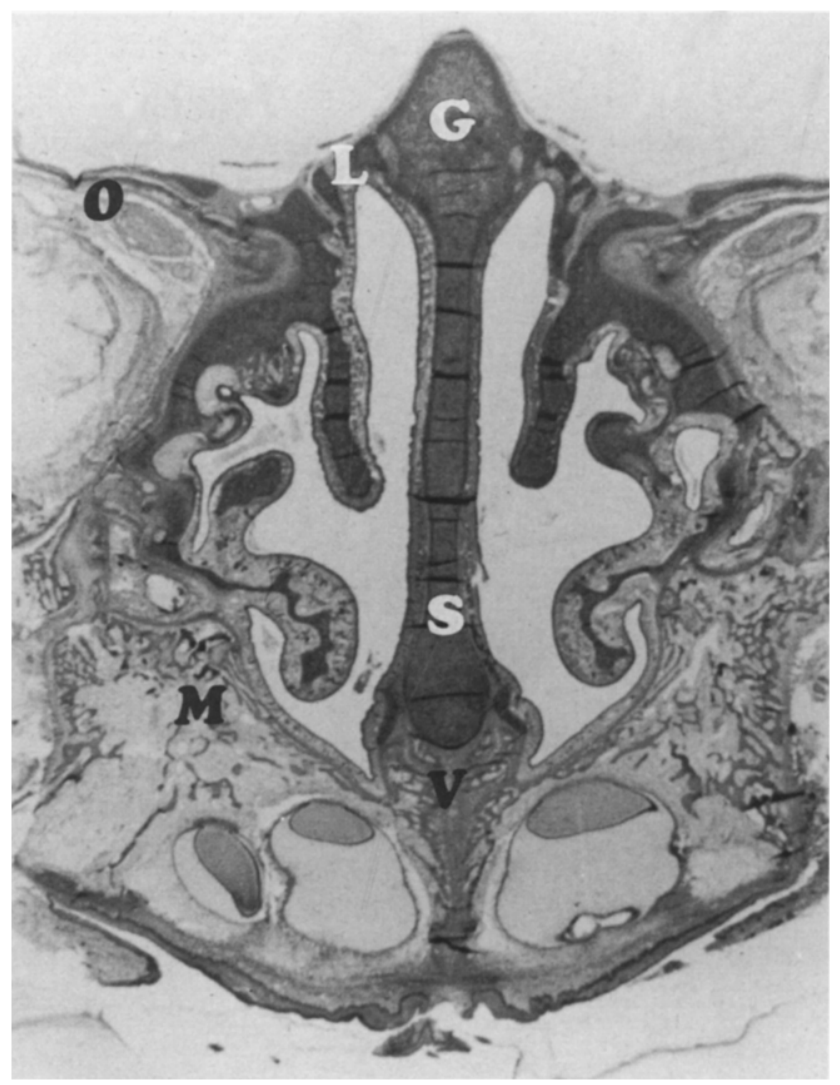

Fig. 1. Photomicrograph of a histological frontal section of a 28-week-old fetus. L, lamina cribrosa; S, nasal septum; V, vomer; $M$, maxilla; $G$, crista galli; $W$, lateral wall; $O$, orbital roof. The nasal fossa is partly filled with meconium and fixation fluid. ( $5 \mu$ parafin section, Alcian Blue/PAS stain). laginous, whereas the greater lateral part of the orbital roof consisted of bone (Fig. 1). MRI showed the early cartilage as a intermediate signal layer between the cerebral hemispheres and the mucosa lining on both sides of the nasal cavities (Fig. 2).

On the other hand, CT showed no density difference between the cartilage and the soft tissues. This resulted in a defect-like discontinuity in the medial part of the anterior skull base (Fig. 3).

\section{Post-natal age group}

A 'defect' as described above was still present on CT of the antcrior skull base in a 1-year-old and 2-year-old (Fig. 4) infant. It was not observed on CT of a 6-yearold child (Fig. 5).

Histological analysis of the base of the skull of the 1-year-old child showed the medial part of the anterior skull base still to be cartilaginous without the presence of any structural defect.

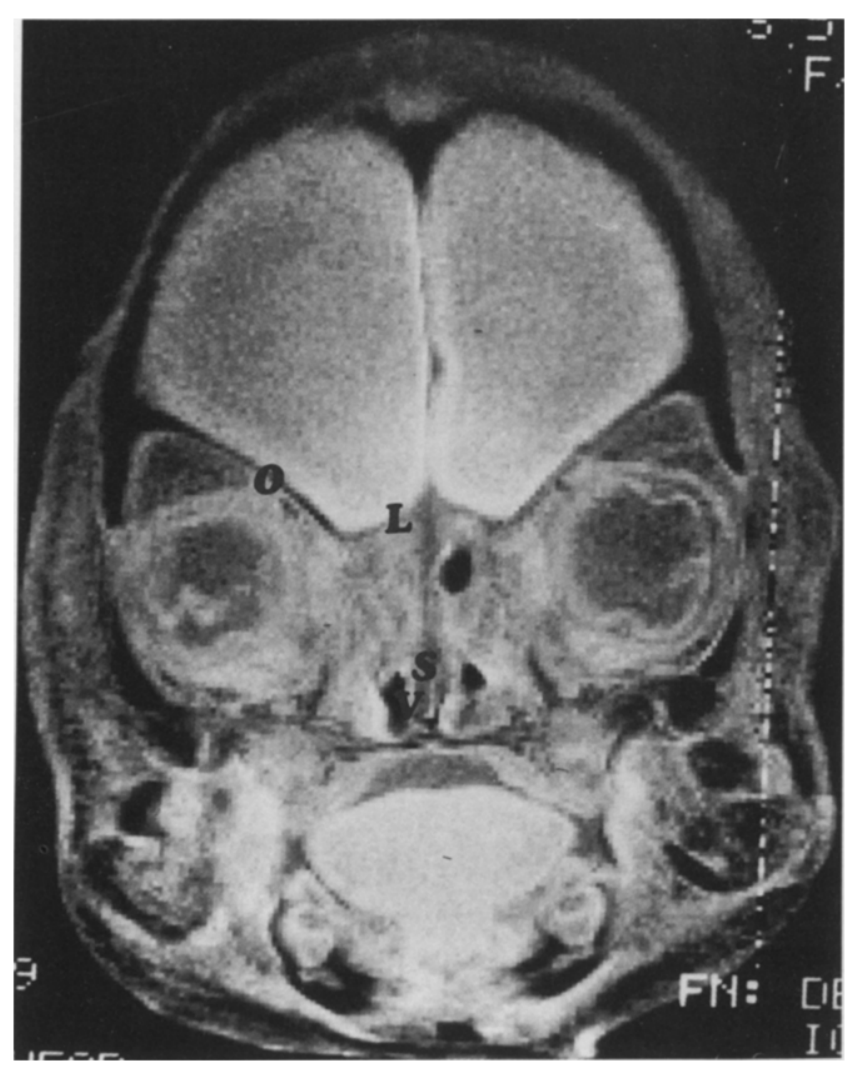

Fig. 2. MRI of the same 28-week-old human fetus as that shown in Fig. 1. Fixed 0.1 M phosphate buffered formaldehyde ( $\mathrm{pH} \mathrm{7.4).} \mathrm{L,}$ lamina cribrosa; S, nasal septum; V, vomer; $O$, orbital roof. Note the cartilaginous (intermediate signal) continuity of the lamina cribrosa where a 'defect' is given in the CT scan image. The nasal fossa is partly filled with meconium and fixation fluid. (Dyna scan, Ciba-Geigy, Zentralforschungs Instituut, Basel, 4.2 Tesla, section thickness $2 \mathrm{~mm}$, T2 weighted image, TR: $2560 \mathrm{~ms}$, TF: $60 \mathrm{~ms}$ ) 


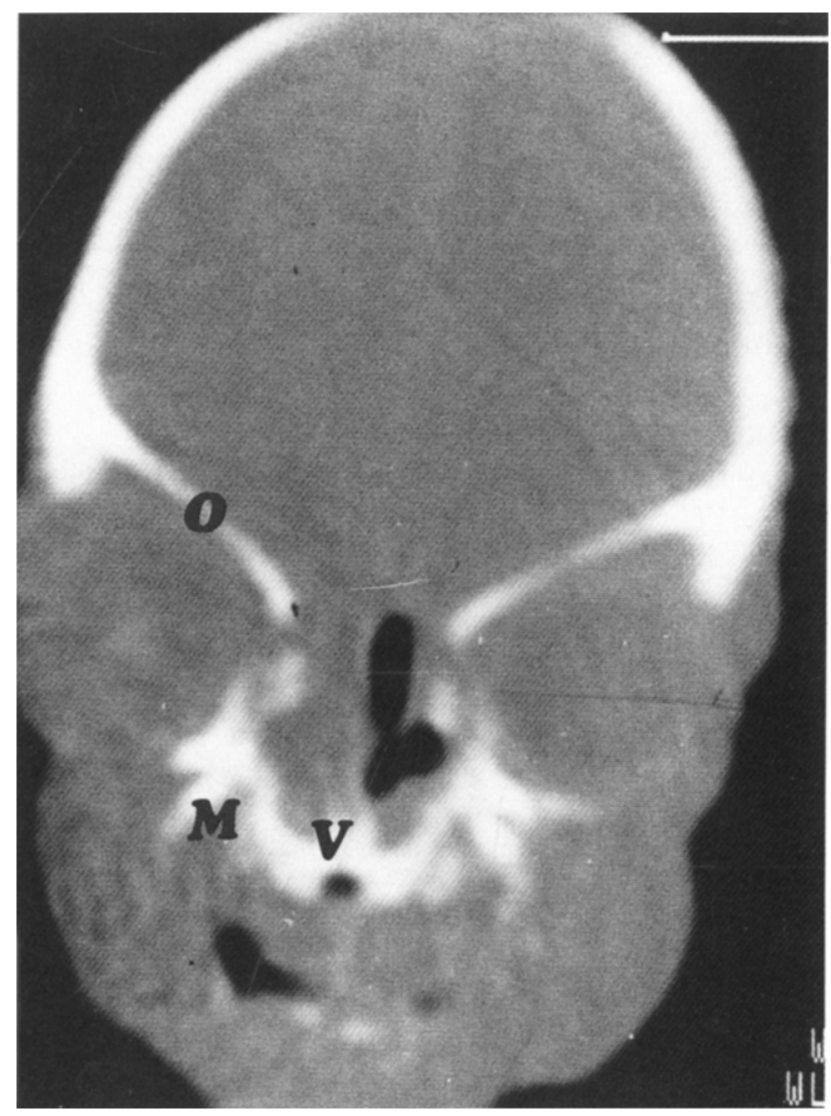

Fig. 3. Coronal CT scan of the human fetus shown in Figs. 1 and 2. Fixed in $0.1 \mathrm{M}$ phosphate-buffered formaldehyde ( $\mathrm{pH} 7.4$ ). V, vomer; M, maxilla; $O$, orbital roof. Note the 'defect' in the base of the skull in the anterior fossa. The right nasal fossa is filled with meconium. (Philips Tomoscan 350, section thickness, $1.5 \mathrm{~mm}$ )

\section{Discussion}

During the first years of life, the observations show that CT does not represent the true nature of structures in the anterior base of the skull. The images obtained are easily misinterpreted and the false assumption was made of a 'defect' where actually a cartilaginous continuity was present. Prior to reconstructive surgery of congenital and anatomical or post-traumatic defects, additional investigations are necessary for a correct evaluation. Perhaps MRI, considering its capability for demonstrating cartilage and soft tissues, will become the optimal modality method of supplying this additional information, especially as it collects and displays its data in very comparable modes.

The finding that the ossification of the lamina cribrosa in this, albeit limited, material takes place between the second and sixth years of life, has not been reported before. Detailed studies of the process of ossification of the different contributing components of the base of the skull are warranted.

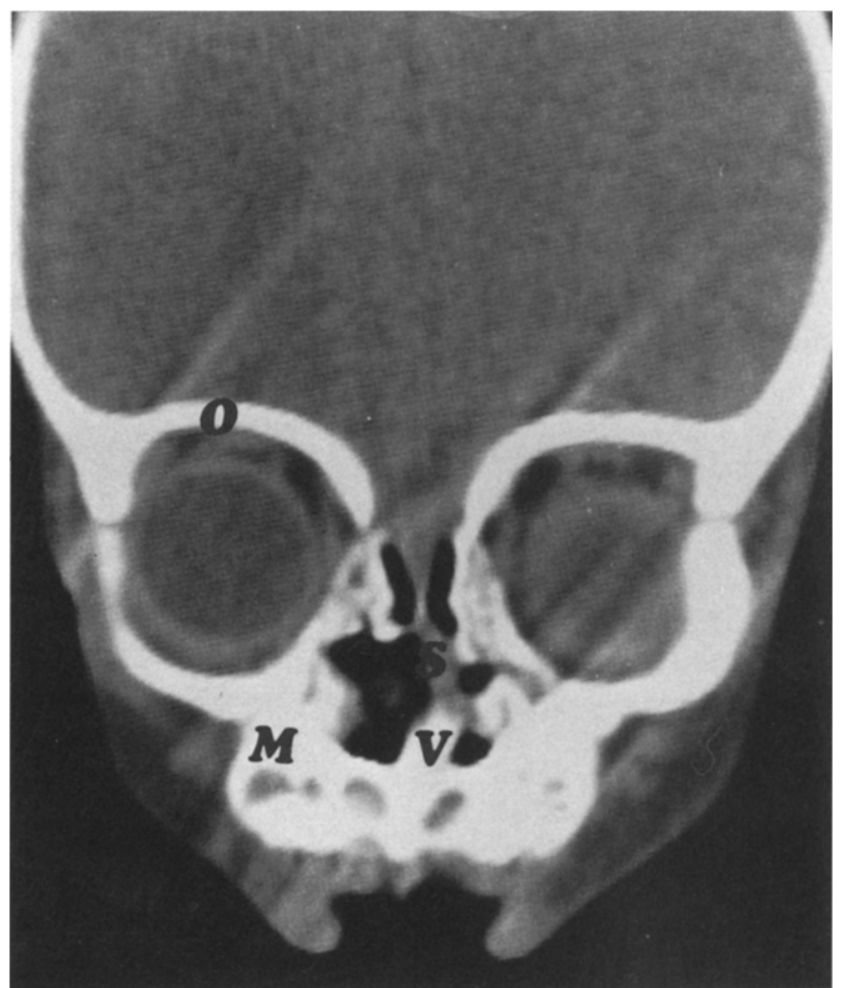

Fig. 4. CT of a 2-year-old infant. S, nasal septum (deviated); V, vomer; $M$, maxilla; $O$, orbital roof. Note persistent 'defect' in lamina cribrosa. (Philips Tomoscan 350, section thickness $1.5 \mathrm{~mm}$ )

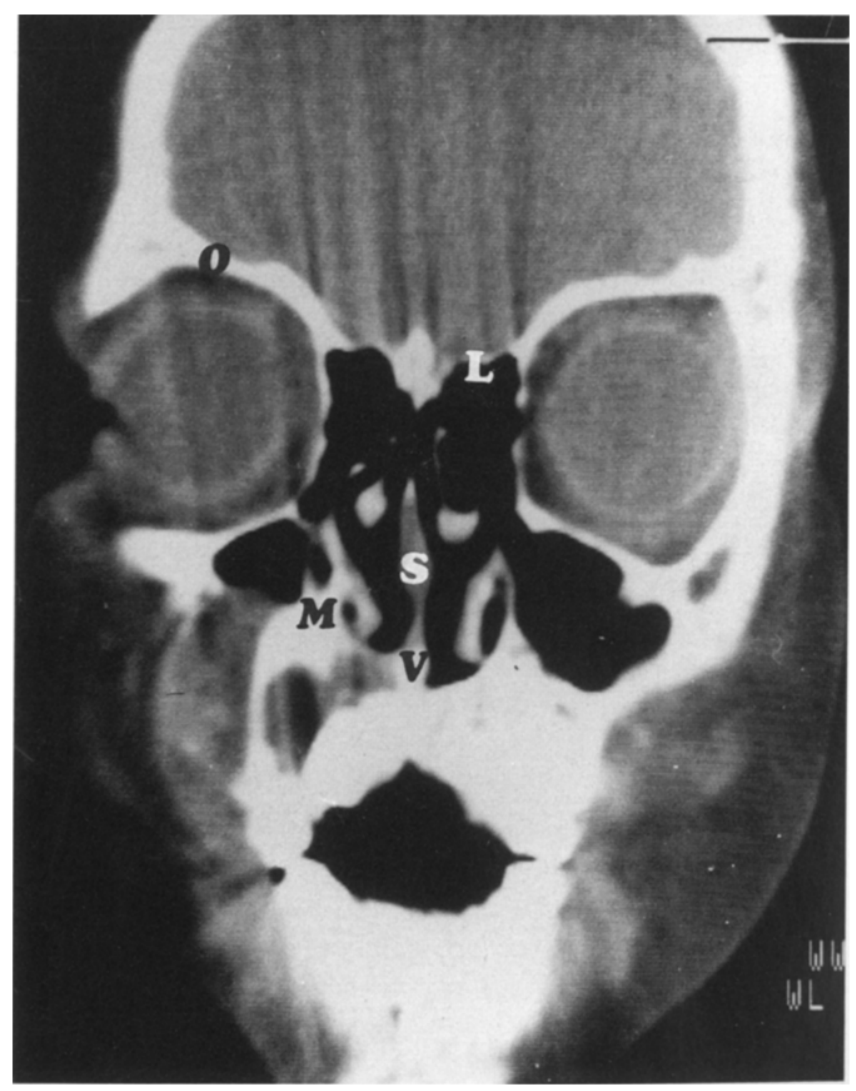

Fig. 5. CT of a 6-year-old infant. L, bony lamina cribrosa; $S$, nasal septum; V, vomer; M, maxilla; O, orbital roof. Note osseous continuity of the basc of the skull. (Philips Tomoscan 350, section thickness $1.5 \mathrm{~mm}$ ) 


\section{Acknowledgements}

The authors are indebted to Dr. P. Alegrini and Dr. G.R. Bullock (Zentralforschungs Institut, Ciba-Geigy Basel) for the use of MRI scan findings derived from a previous collaborative study reported on separately [13], and to Dr. H.L. Verwoerd-Verhoef for her suggestions.

\section{References}

1 Schaeffer JP. The nose, paranasal sinuses, nasolacrimal passageways and olfactory organs in man. Philadelphia: P. Blakiston's Son, 1920.

2 Mugnier A. Embryologie et développement bucco-facial. Masson et Cie, Paris: Masson et Cie, 1964

3 Hamilton WJ. Boyd, JD. Mossman, WH. Human embryology; prenatal development of form and function. 4th Ed. Cambridge: W. Heffer and Sons, 1972.

4 Van Loosen J, Van Velzen, D. Cartilaginous structures in human midfacial development. Ped Pathol 1989; 8: 350.
5 Fawcett $\mathrm{E}$. The development of the human maxilla, vomer and paraseptal cartilages. J Anat Lond 1911; 45: 378-405.

6 De Beer GR. The development of the vertebrate skull. Oxford: Oxford University Press, 1937.

7 Scott JH, The cartilage of the nasal septum. Br Dent J 1953; 95: 37-43.

8 Van Loosen J, Verwoerd-Verhoef HL, Verwoerd CDA. The nasal septal cartilage in the newborn. Rhinology 1988; 26: 161-165.

9 Poublon RML, Verwoerd CDA, Verwoerd-Verhoef HL. Anatomy of the upper lateral cartilages in the human newborn. Rhinology 1989; in press.

10 Ford EHR. Growth of the human cranial base. Am J Orthodont 1958; 44: 498-506.

11 Krmpotic-Nemanic J. Entwicklungsgeschichte und Anatomie der Nase und der Nasennebenhöhlen. In Berendes J, Link R, Zollner F, eds, Hals Nasen Ohrenheilkunde in Praxis und Klinik. Stuttgart: Georg Thieme Verlag, 1977; 1: 1-36.

12 Fairbanks DNF. Embryology and Anatomy. In: Bluestone CD, ed. Pediatric Otolaryngology, Philadelphia: Saunders, 1983; 647-678.

13 Allegrini P, Van Velzen D, Van Loosen J, Bullock GR. MRI analysis of maturing cartilage in developing midfacial structures. Int J MRI 1990; 2: in press. 